\title{
A Novel Method for Monitoring SpO2 in Wearable Health Monitoring Applications
}

\author{
Priyam Singh, Farzana Shaik, Princy Eunice, Isaac Luther, R.Sai.Deepthi, Yatavakilla Amarendra Nath,
}

\begin{abstract}
This study outlines the utility of a reflectance pulseoximeter sensor in Wearable Health Monitoring System (WHMS). Pulseoximeter has its own vital role in WHMS as it can provide additional crucial information about the physiological status. This paper discusses the data analysis for ambulatory utility of a reflectance pulseoximeter for variable locations on the body e.g. Finger, forehead, chest. Different physical factors affecting the performance of spo2 sensor are considered and discussed. An experiment simulating ambulation was conducted with Nonin reflectance sensor against standard sensor is capable for its utility in variable motions. We also compared variable locations data against standard positions like Forehead and Fingertip during rest conditions, the outcome of which proved that the Manubrium sternum can be utilized as a site of location for the measurement of spo2 with respect to a single emitter and detector sensor.
\end{abstract}

Keywords: Wearable Health Monitoring, Manubrium Sternum, Reflectance Pulseoximetry

\section{INTRODUCTION}

The increase in population and cost of health care has made wearable health monitoring a key tool in health care industry [1]. Technology advancements in wireless networking, micro fabrication and miniaturized physical sensors, has created a new era in portable health care monitoring industry [2]. An individual's health status can be ascertained by monitoring the vital parameters such as pulse rate, oxygen saturation of blood, blood pressure etc [3]. There are many wearable physiological monitoring systems proposed and developed such as Smart Vest [4], AMON [5], Lifeshirt [6], LifeGuard [7], which don't use a reflectance Pulseoximetry. The systems such as Hidalgo Equivital [8] and Zypher [9]

Revised Manuscript Received on December 15, 2019

Priyam Singh, Biomedical Department, Electronics \& Communications Engineering,Vignan's foundation for science technology \& research (deemed to be university) Vadlamudi - 522213 , India

Farzana Shaik, Biomedical Department, Electronics \& Communications Engineering,Vignan's foundation for science technology \& research (deemed to be university) Vadlamudi - 522213 , India

Princy Eunice, Biomedical Department, Electronics \& Communications Engineering,Vignan's foundation for science technology \& research (deemed to be university) Vadlamudi - 522 213, India

Isaac Luther, Biomedical Department, Electronics \& Communications Engineering,Vignan's foundation for science technology \& research (deemed to be university) Vadlamudi - 522 213, India

R.Sai.Deepthi , Biomedical Department, Electronics \& Communications Engineering,Vignan's foundation for science technology \& research (deemed to be university) Vadlamudi - 522 213, India

Yatavakilla Amarendra Nath, Biomedical Department, Electronics \& Communications Engineering,Vignan's foundation for science technology \& research (deemed to be university) Vadlamudi - 522 213, India has the facility to use a reflectance-pulseoximetry in which sensor is placed on forehead but may not be very comfortable to user while performing routine activities and definitely notadvised to use in continuous monitoring. Continuous monitoring of vital parameters of human body requires an unobstructive yet comfortable placement and ergonomic design of sensor, which will be less prone to motion artifacts due to routine activities.

Conventionally pulseoximeters are placed on finger, earlobe and forehead for the measurement of $\mathrm{SpO} 2$. Continuous utility of earlobe or forehead (Ideal locations for wearable monitoring) is not advised as measured spo2 becomes inconsistent and uncomfortable to the user. This paper explores other suitable locations for the placement of $\mathrm{SpO} 2$ sensor aiding for comfortable and long- term monitoring with respect to a single reflectance based NONIN sensor.

\section{MATERIALS\& METHODS}

Nonin OEM-III module with development kit, NoninTransreflectance sensor (8000R) was used for obtaining the $\mathrm{SpO}$, Nellcor finger clip sensor with module is taken as a standard reference for validating the Nonin OEM sensor during rest and basic physical activities. Statistical analysis is performed using MedCalc software.

\section{Methodology:}

Initial study was performed on 10 different subjects by placing the NONIN SpO2 sensor on forehead with the Sponge integrated sticker provided by NONIN, and Nellcor Finger clip sensor is attached to the finger as reference. The individual subject is asked to perform different activities such as rest or sitting, walking, cycling, head movement and eyebrow movement simulating motion artifacts. Resting is normally a seated position without moving any parts of body, walking is a brisk walk without shaking the hands as the nellcor sensor is placed on the hand, similarly cycling is performed without hand movement on bicycle ergo-meter. Head movement and eye movement will not lead to movement in finger, care is taken such that finger will not move in any activity, as any movement of hand may lead to erroneous $\mathrm{SpO} 2$ values. Each activity was performed for 2 minutes and overall data was collected for 10 minutes per individual. 
The study was then extended to explore a suitable location for the placement of $\mathrm{SpO} 2$ sensor other than forehead as it's not a suitable place for long-term monitoring in addition user acceptance is very low as the sensor is visible on his face. To make the sensor more ergonomic and comfortable while worn, we had carried out different experimental procedures to identify an equivalent against the conventional position on human body.

Considering the previous studies stating that $\mathrm{SpO} 2$ measurement by reflectance pulseoximetry can be used on chest [10]. The specific location such as Manubrium was previously tried for the measurement of $\mathrm{SpO}_{2}$ [11]. Certain physical factors were considered with respect to sensor position explaining the importance of perfusion [12]. The angular position, component distance and photosensitive area were considered during the placement of sensor on sternum [13].

We have selected three different places on chest for the placement of sensor i.e. 1. Manubrium sternum 2. Left mid-

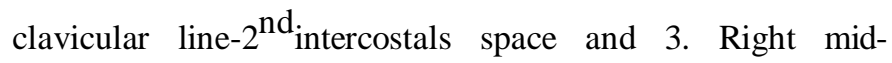
clavicular line $2^{\text {nd }}$ intercostals space, as shown in figure 1 , Simultaneously $\mathrm{SpO} 2$ was monitored from Nonin 8000R sensor on forehead and Nellcor finger clip sensor as a second reference. The data was collected from 10 different individuals during rest condition with repeated measurements at different intervals by placing the sensor on described locations.

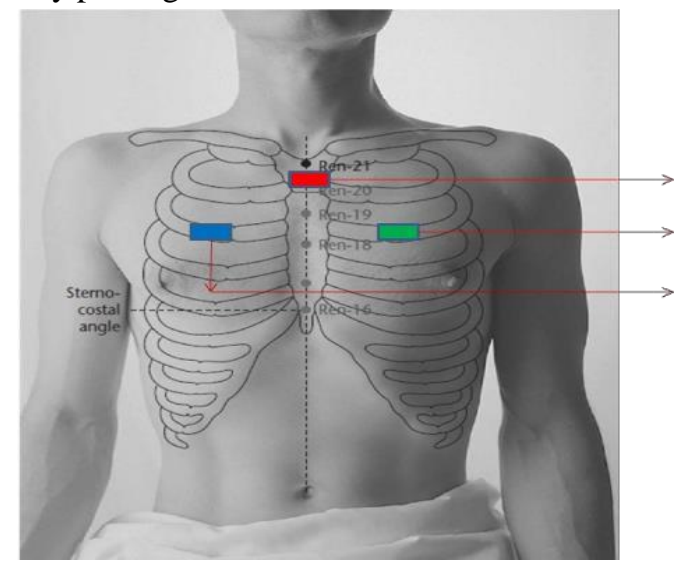

Figure 1: Spo2 at different places on chest

\section{RESULTS}

The results indicate Nonin forehead sensor can be used in wearable applications when compared to a standard Nellcor sensor as the paired t-test showed a mean difference of 0.82 and a standard deviation not exceeding 1.3. The resulting $P$ value was 0.0001 .The averaged $\mathrm{spo} 2$ values from the two sensors are represented in figure 2.

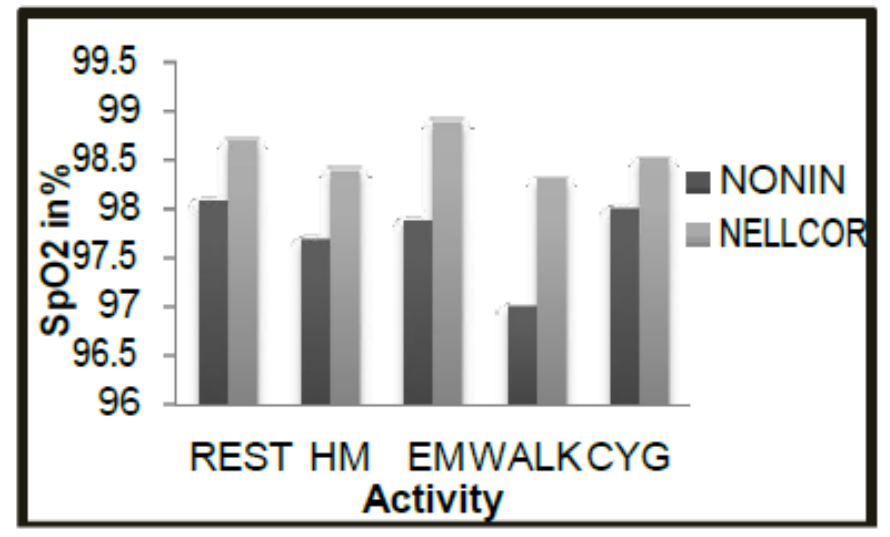

Figure2: Comparative results of averaged $\mathrm{SpO} 2$ (in \%) recorded during basic physical activities. In the above graph (HM - head movement, EM- eyebrow movement, CYG- cycling)

In figure3, scatter plot represents the data collected among 10 different subjects during rest condition. The scatter plot gives a clear picture that the Manubrium and forehead $\mathrm{SpO} 2$ values are similar, the comparative mean difference between Finger, Forehead and Manubrium is not more than $\pm 2 \%$. The other two locations showed variation greater than $8-10 \%$.

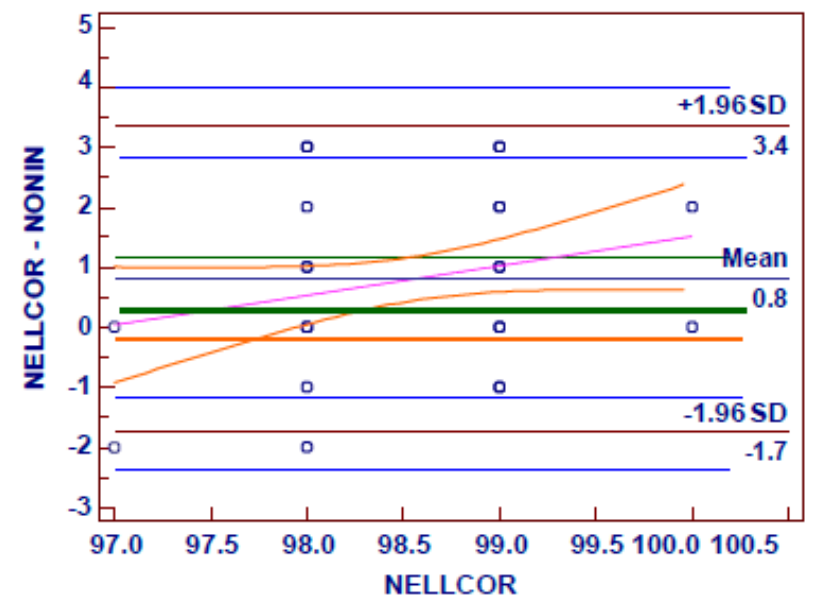

Figure3: Bland-Altman plot of $\mathrm{SpO} 2$ recorded during basic physical activities with Nellcor finger clip sensor as a standard.

Figure 3 shows the Bland-Altman plot of $\mathrm{SpO} 2$ data. The plot clearly illustrates that the difference of $\mathrm{SpO}_{2}$ values during different activities is within $\pm 3 \%$, which adheres to clinical standards during rest condition. 


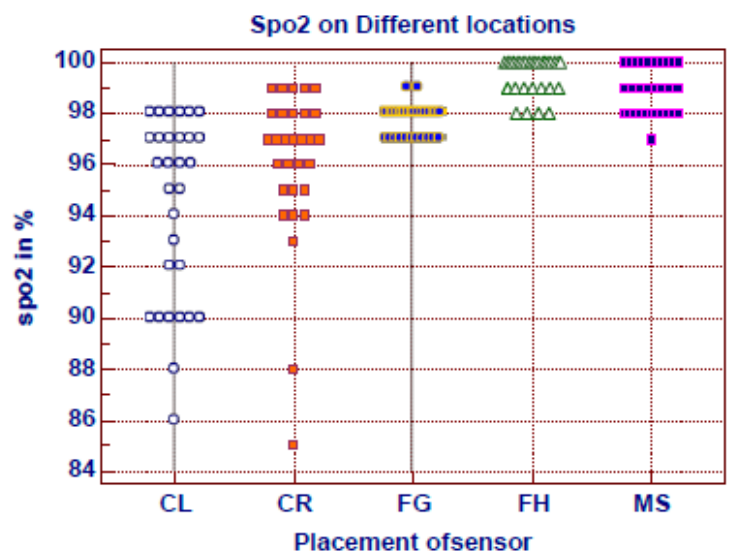

Figure3: Scatter plot of $\mathrm{SpO}_{2}$ values (in \%) recorded during rest by placing the sensor on different places of human body. [In Graph CL-chest left midcalavicular line, CR- chest right midclavicular line, FG-finger clip sensor, FH- forehead, MSManubrium)

\section{DISCUSSION \& CONCLUSION:}

The placement location of $\mathrm{SpO}_{2}$ sensor in wearable health monitoring system is finalized and presented. After several experimental recordings and data analysis of $\mathrm{SpO}_{2}$

valuesfrom various positions on human body, just above the Angle of Lewis (the little bony protuberance, where the body of sternum joins the Manubrium) is identified as the exact location for the placement of $\mathrm{SpO} 2$ sensor. The LED - PD (Photo detector) distance available in NONIN transreflectance $8000 \mathrm{R}$ sensor is suitable for obtaining $\mathrm{SpO}_{2}$ values from chest is observed in the study.

In conclusion, we have shown $\mathrm{SpO} 2$ can be successfully measured on the Manubrium and the quality and repeatability of measurements are comparable to commercially available finger-and forehead based systems, hence the study is progressed further for integration of sensor into Wearable Remote Health Monitoring Belt.

Our future study will progress towards Ambulatory monitoring of $\mathrm{SpO}_{2}$ recordings on different subjects performing different physical activities of daily living.

\section{ACKNOWLEDGEMENT}

We are grateful to Vignan's Foundation for Science technology and Research University for providing financial support and research facility for this work.

\section{REFERENCES}

1. U. Varshney, "Wireless Networks for Enhanced Monitoring of Patients," Int'l J. Healthcare Technology and Management, vol. 6, no. 4/5/6, 2005, pp. 489-499.

2. E. Kafeza et al., "Alerts in Mobile Healthcare Applications: Requirements and Pilot Study," IEEE Trans. Information Technology in Biomedicine, vol. 8, no. 2, 2004, pp. 173-181

3. http://www.cefastechnology.co.uk

4. P. S. Pandian, K. Mohanavelu, K. P. Safeer, T. M. Kotresh, D. T. Shakunthala, P. Gopal and V. C. Padaki, "Smart Vest: wearable multiparameter remote physiological monitoring system," Med. Eng. Phys., 30: 466-477, 2008 .
5. U. Anliker, J. A. Ward, P. Lukowicz, G. Troster, F. Dolveck, M. Baer, F. Keita, E. B. Schenker, F. Catarsi, L. Coluccini, A. Belardinelli, D. Shklarski, M. Alon, E. Hirt, R. Schmid and M. Vuskovic, "AMON: a wearable multiparameter medical monitoring and alert system," IEEE Trans. Inf.Technol. Biomed., 8: 415-427, 2004

6. P. Grossman, "The LifeShirt: a multi-function ambulatory system monitoring health, disease, and medical intervention in the real world," Stud. Health Technol. Inform., 108: 133-141, 2004.

7. S. Park and S. Jayaraman, "e-Health and quality of life: the role of the Wearable Motherboard," Stud. Health Technol. Inform., 108: 239-252, 2004.

8. http://www.equivital.co.uk/

9. .http://www.zephyrtechnology.com/products/biohar ness-3/

10. A Novel Hybrid Reflectance Pulseoximeter sensor with improved linearity and General applicability to various portions of the body. 